CIC. Cuadernos de Información y Comunicación ISSN: 1135-7791

http://dx.doi.org/10.5209/CIYC.55969

\title{
Del muro a la pantalla: el graffiti en la cibercultura.
}

\author{
Israel Márquez ${ }^{1}$
}

Enviado: 21 de abril de 2017 / Aceptado: 23 de abril de 2017

Resumen. Este texto reflexiona sobre el modo en que Internet y las nuevas tecnologías digitales han transformado la experiencia y el significado del graffiti en los últimos años. La cultura actual del graffiti es inseparable de su visualización y puesta en circulación a través del tipo de pantallas interactivas y en red que hoy dominan nuestro espacio comunicativo y nuestros procesos de mediación. En este sentido, el artículo argumenta que la pantalla se ha convertido en el nuevo "muro" del graffiti contemporáneo, la superficie principal donde actualmente convergen todas las prácticas y experiencias de graffiti y del denominado street art o postgraffiti.

Palabras clave: graffiti; street art; pantalla; cibercultura; Internet; semiótica.

\section{[en] From the wall to the screen: graffiti on cyberculture}

Abstract. This text reflects on how Internet and new digital technologies have transformed the meaning of graffiti in recent years. Current graffiti culture is inseparable from its visualization and circulation through the type of interactive and networked screens that today dominate our communicative space and our mediation processes. In this sense, the article argues that the screen has become the new "wall" of contemporary graffiti, the main area where all practices and experiences of graffiti and the so-called street art or postgraffiti converge.

Keywords: graffiti; street art; screen; cyberculture; Internet; semiotics.

Sumario. 1. Introducción. 2. Breve historia del graffiti. 3. Graffitis, archivos y pantallas. 4. Los viajes del graffiti: del metro a Internet. 5. Street art/postgraffiti, o el transeúnte como participante. 6. Conclusiones. Referencias.

Cómo citar: Márquez, I. (2017). Del muro a la pantalla: el graffiti en la cibercultura, en CIC. Cuadernos de Información y Comunicación 22, 95-106.

"Graffiti lives!"

Graffiti visto en una pantalla

\section{Introducción}

El graffiti es una de las formas culturales más importantes, innovadoras y transgresoras de los últimos tiempos, heredera de movimientos artísticos subversivos como

1 Investigador Postdoctoral "Juan de la Cierva" (MINECO) .Universitat Oberta de Catalunya (UOC).

Email: isravmarquez@gmail.com 
el futurismo, el dadaísmo, el situacionismo o el punk. Desde sus inicios, el graffiti como fenómeno social, estético, político y comunicativo ha despertado el interés de varios autores procedentes de disciplinas diversas. Para García Canclini (1990: 314), por ejemplo, el graffiti es un género impuro y "constitucionalmente híbrido", un lugar de intersección entre lo visual y lo literario, lo culto y lo popular, cuyo "trazo manual, espontáneo, se opone estructuralmente a las leyendas políticas o publicitarias 'bien' pintadas o impresas, y desafía esos lenguajes institucionalizados cuando los altera". Joan Garí, en un libro fundamental sobre el tema, define el graffiti como "un código o modalidad discursiva en el que emisor y receptor realizan un particular diálogo - desde el mutuo anonimato- en un lugar donde éste no está permitido, construyendo con diferentes instrumentos un espacio escriturario constituido por elementos pictóricos y verbales en osmosis y amalgama recurrente" (1995: 26; cursivas en el original). Para Martín Barbero (1987; 2008), los graffiti son formas de creatividad estética popular ciudadana, lugares de mestizaje discursivo y de afirmación del territorio a través de una escritura/textualidad pública que, como la ciudad misma, "se deshace y rehace día a día en muchos idiomas y con muy diferentes materiales" (Martín Barbero, 2008: 220).

Como vemos a partir de estas definiciones, el graffiti constituye un objeto de estudio complejo y poliédrico en el que se dan cita diferentes cuestiones y problemas de carácter semiótico, artístico, social, político, etc. Recientemente, este tipo de escritura/pintura mural se ha complejizado aún más, incluyendo nuevas formas, intervenciones y técnicas englobadas bajo lo que se ha dado en llamar street art o postgraffiti. Pero si por algo se diferencia la práctica y experiencia graffitera de los últimos años es por la importancia que han adquirido Internet y las -ya no tan nuevas- tecnologías digitales en sus dinámicas de creación, distribución, consumo y socialización, así como por el decisivo papel que ha adquirido la pantalla como superficie/interfaz fundamental de todos estos procesos. De alguna manera, a raíz de su digitalización, el graffiti ha acabado "pantallizándose", en el sentido de que se ha vuelto completamente inseparable de su visualización y puesta en circulación a través del tipo de pantallas interactivas y en red (ordenadores, smartphones, tablets) que hoy dominan nuestro espacio comunicativo y nuestros procesos de mediación (Cardoso y Lima, 2013). El objetivo de este artículo es, por tanto, analizar cómo la experiencia del graffiti se ha ido "pantallizando" durante los últimos años; o dicho de otro modo, observar cómo el espacio digital de la pantalla se ha convertido en el nuevo "muro" -móvil, fluido, dinámico- del graffiti contemporáneo.

\section{Breve historia del graffiti}

El término graffiti procede del italiano graffiare (garabatear) y ha sido empleado tradicionalmente para describir muchos tipos diferentes de escritura/pintura mural, desde las pinturas rupestres de la prehistoria hasta los denominados "latrinalia" (las inscripciones encontradas en las letrinas de la antigua Roma) y "toda la suerte de mensajes políticos, sexuales o humorísticos que han sido garabateados, pintados o marcados en las paredes a lo largo de la historia" (Castleman, 1987: 10). En realidad, la práctica del graffiti es el testimonio de un impulso y una necesidad básica del ser humano: expresarse y comunicarse por medio de dibujos y palabras (Stahl, 2009). 
Así mismo, el graffiti pone de manifiesto la importancia que durante siglos ha tenido el muro como medio de comunicación, algo difícil de imaginarnos en una época dominada por todo tipo de artefactos y soportes mediáticos. En efecto, hay que recordar que durante mucho tiempo muros y paredes han sido las principales superficies de comunicación y de producción artística del ser humano. Como señala Garí (1995: 21), "los espacios parietales se han constituido en soporte de escritura en muchas civilizaciones, y también han sido, hasta el siglo XIV, la superficie principal en que se ha llevado a cabo la producción artística".

El graffiti es, por tanto, una práctica humana antigua y persistente, visible en el hecho de que en la historia de la humanidad siempre ha habido signos garabateados en las paredes. Sin embargo, el término, tal y como lo conocemos actualmente, se relaciona más estrechamente con un tipo particular de pintadas que se desarrollaron en la ciudad de Nueva York durante la segunda mitad del siglo XX y que terminaron convirtiéndose en el modelo predominante de graffiti. Este tipo de graffiti existió como entidad cultural independiente hasta principios de los años 80 , pero a partir de entonces pasó a formar parte de los "cuatro elementos" fundamentales de la naciente cultura hip hop, junto con el rap, el DJing y el breakdance. Cada uno de estos elementos revelaba una dimensión diferente de la cultura hip hop. El rap destacaba el componte oral a través de las rimas y el canto, el DJing hacía énfasis en la dimensión sonoro-musical a través de prácticas como el scratch, el sampleado y el remix, el breakdance incidía en el aspecto físico y performativo a través del baile, y el graffiti destacaba el componente visual a través de la escritura y pintura en muros y otras superficies parecidas (vagones de metro, puertas, señales de tráfico, etc.). La unión de estos cuatro elementos destaca el carácter semióticamente heterogéneo y multisensorial del hip hop, una de las manifestaciones culturales y artísticas más ricas y productivas del siglo $\mathrm{XX}$, y ejemplo paradigmático de cómo los guettos y los suburbios (en este caso el Bronx y Harlem) constituyen ámbitos de efervescencia artística y espacios de creatividad e innovación en un principio rechazados pero después incorporados a la cultura mayoritaria (Hatzfeld, 2007).

El modelo neoyorquino de graffiti se difundió en el contexto de la incipiente cultura hip hop -de ahí que también se le conozca como "graffiti hip hop"-, en un principio hacia el resto de ciudades de los Estados Unidos, y más tarde, a otros países del mundo. Para ello resultaron fundamentales una serie de películas que supieron retratar e internacionalizar este tipo de graffiti y el fenómeno de la cultura hip hop en su conjunto: Wild Style (1983), Style Wars (1983), y Beat Street (1984). Estas películas contribuyeron decisivamente a visibilizar la práctica del graffiti, y más importante aún, convirtieron las creaciones neoyorquinas en el punto de referencia esencial para todos aquellos interesados en esta nueva forma de expresión artística. Junto a estas películas, el trabajo de autores como Martha Cooper y Henry Chalfant, dos de los primeros fotógrafos en documentar los orígenes del graffiti y la cultura hip hop en Nueva York, fue igualmente decisivo a la hora de internacionalizar este modelo y convertirlo en predominante. Su libro conjunto Subway Art, publicado en el año 1984 por la editorial europea Thames \& Hudson, llegó a ser considerado como "la Biblia del graffiti" y sirvió durante mucho tiempo como manual de instrucciones y fuente de inspiración para adolescentes de distintas partes del mundo, quienes empezaron a imitar este tipo de graffiti en sus propias ciudades.

Todos estos aspectos ayudaron a crear la imagen del graffiti que tenemos actualmente, y que se correspondería con este tipo de graffiti moderno de origen neoyor- 
quino que después ha sido imitado y readaptado en diferentes contextos urbanos a lo largo del planeta. Si bien estos graffiti empezaron como sencillas pintadas de nombres y apodos en muros y otras superficies -en especial los vagones del metro, el espacio preferido por los escritores neoyorquinos-, pronto evolucionaron hacia formas visuales más complejas y barrocas, con ramificaciones de estilo y de escuela ligadas a las diferentes bandas o "crews" de graffiteros.

Más allá de las cuestiones estilísticas, lo más importante de esta forma moderna de graffiti reside en su función simbólica, sintetizada en la famosa expresión inglesa "Getting Up", esto es, "dejarse ver" o "hacerse ver". Aparte de ser el título de uno de los estudios más importantes sobre el graffiti neoyorquino, ${ }^{2}$ esta expresión resume perfectamente el objetivo principal de estos pioneros del graffiti moderno: escribir o pintar profusamente tu nombre de manera que éste aparezca continuamente, o por lo menos, con mucha frecuencia. En este "dejarse" o "hacerse ver" de manera prolífica reside la directriz primordial del graffiti neoyorquino, más allá de otras cuestiones como la del estilo. Esta idea queda perfectamente ilustrada en la siguiente cita del graffitero Tracy 168: "El estilo no significa nada si tu nombre no aparece con frecuencia ¿Cómo va a conocer la gente tu estilo si no ve obras tuyas?" (citado en Castleman, 1987: 29). De hecho, los graffiteros neoyorquinos adquirían fama y popularidad gracias a su alto índice de productividad, y adquiría el título de "rey de la línea" el escritor cuyo nombre aparecía más veces en una línea de metro determinada, independientemente de cómo fuera su estilo. Así pues, existe en este tipo moderno de graffiti un énfasis en la cantidad, en el "difundir" y "hacer ver" los nombres con asiduidad, que diferenciaría este tipo de intervención urbana de otras formas tradicionales de escritura mural.

Este énfasis en la cantidad no implica necesariamente que el estilo no sea un elemento importante en el graffiti moderno. Así, como decíamos antes, este tipo de graffiti ha ido evolucionando hacia formas visuales más elaboradas y complejas, pero en su esencia conserva algunos rasgos comunes, como por ejemplo la importancia del color, o la influencia de modelos y personajes procedentes de la cultura massmediática, desde el cómic a la televisión, hasta la música pop y los dibujos animados. Estos rasgos se conservan incluso en muchas obras del denominado street art, un término popularizado en los últimos años y que vendría a ser una forma ampliada o expandida de graffiti, una especie de graffiti más allá del graffiti -de ahí que el street art también sea conocido como postgraffiti.

\section{Graffitis, archivos y pantallas}

Tras este breve pero necesario repaso por la historia y elementos del graffiti moderno, conviene centrarnos ya en el objetivo principal de nuestro artículo: analizar cómo Internet y las tecnologías digitales han transformado el significado y la experiencia del graffiti en los últimos años, o por decirlo de otro modo, entender cómo el graffiti

Nos referimos al libro Getting Up. Subway Graffiti in New York, de Craig Castleman. Existen dos traducciones al castellano de este libro, ambas realizadas por Pilar Vázquez. La primera fue publicada en el año 1987 por la editorial Hermann Blume bajo el título de Los graffiti y es la versión que manejamos en este artículo. La segunda versión fue publicada en el año 2012 por la editorial Capitán Swing bajo el título de Getting Up/Hacerse ver. El grafiti metropolitano en Nueva York. 
se ha ido desplazando del espacio físico del muro -y sus extensiones metonímicas (vagones, puertas, mobiliario urbano, etc.)- al espacio digital de la pantalla. Para llevar a cabo esta tarea, parto de la evidencia de que el graffiti actual es inseparable de la mediación de las pantallas, en el sentido de que éstas son hoy en día interfaces fundamentales en la producción, distribución y recepción de todas las formas contemporáneas de graffiti. Si bien en el pasado pantallas como la cinematográfica o la televisiva jugaron un papel importante en la difusión e internacionalización de ciertas imágenes del graffiti -a través de películas como las señaladas en el apartado anterior-, en la actualidad las pantallas son un elemento totalmente inseparable de la experiencia graffitera. Y por pantallas aquí me refiero más específicamente a aquellas pantallas directamente relacionadas con Internet y la cibercultura, esto es, las pantallas de los ordenadores, los smartphones y las tablets, el tipo de pantallas interactivas y "en tiempo real" que han acabado dominando la moderna cultura visual (Manovich, 2006) y que se articulan no ya en torno al modelo tradicional de comunicación de masas (como la pantalla cinematográfica o la televisiva) sino a partir del modelo de comunicación en red (Cardoso y Lima, 2013).

Realizar un graffiti hoy en día implica capturarlo rápidamente con una (o varias) de estas pantallas interactivas, archivarlo, y distribuirlo por Internet para que llegue a otras pantallas. En realidad, esta voluntad -o, recordando a Derrida (1997)- "mal de archivo", ha estado presente desde los mismos orígenes del graffiti moderno y tiene que ver con un aspecto fundamental de esta práctica artística: su fugacidad. El graffiti es un arte hecho para ser destruido. Muchas piezas de graffiti apenas duran unos pocos días en las calles, hasta que son borradas por los servicios municipales de limpieza o por empresas especializadas en la limpieza de graffitis y el borrado de pintadas. Otros materiales como carteles o pegatinas -más usados en el contexto del street art- son incluso más fáciles de eliminar, pues no quedan adheridos a la superficie de fondo de forma natural, como sí ocurre con el graffiti. Así pues, el graffiti es un arte efímero. De ahí la necesidad de fotografiar, archivar y "resucitar" -analógica o digitalmente- sus obras, dotándolas, así, de una cierta perdurabilidad e incluso inmortalidad.

Como decíamos, esta voluntad o pulsión archivística ha estado presente desde los mismos orígenes del graffiti neoyorquino, como demuestra el importante trabajo de documentación llevado a cabo por fotógrafos como Cooper y Chalfant. Sin embargo, la documentación de este tipo de graffiti no fue realizada por los propios graffiteros, sino por aquellos que tenían acceso a cámaras y equipos profesionales. Los graffiteros de Nueva York, la mayoría de ellos jóvenes negros o portorriqueños residentes en guettos, no disponían de los recursos económicos para comprarse una cámara fotográfica. La única forma que tenían de documentar su escena por ellos mismos y no depender del trabajo profesional de otros era alquilar o incluso robar las cámaras. ${ }^{3}$

Esto ha cambiado completamente en el graffiti actual, dada la ubicuidad de dispositivos móviles con cámaras integradas y conexión a Internet como los smartphones, y la reducción continuada de sus precios. Las nuevas generaciones de graffiteros, muchos de ellos operando en el contexto más amplio del street art o postgraffiti, pueden hoy en día fotografiar, archivar y distribuir sus piezas con sus propios me-

Castleman (1987) ha explicado con bastante detalle cómo existe entre los escritores de graffiti la tradición de robar o "mangar" (Racking Up) los materiales que utilizan, especialmente los sprays, rotuladores y otros materiales necesarios para llevar a cabo sus piezas. 
dios y dispositivos De hecho, estos actos de captación y archivo son ya complemente inseparables de la propia práctica graffitera, son una parte más de este proceso. Por tanto, la fotografía, documentación y archivo del graffiti no es ya una cuestión profesional, como lo fue en sus orígenes, sino algo llevado a cabo por sus mismos representantes, quienes pueden ahora subir sus propias creaciones a la red y, a través de ella, hacerlas circular y "viajar" por diferentes tiempos y lugares, por diferentes pantallas e interfaces...

\section{Los viajes del graffiti: del metro a Internet}

Este último punto nos conduce a otro aspecto importante del graffiti actual: su diseminación digital instantánea a través de Internet (Irvine, 2012), o lo que es lo mismo, su "viaje electrónico" o "pantallológico" en forma de datos. A pesar de asociarse con un espacio eminentemente estático como es el muro, lo cierto es que el graffiti moderno siempre ha aspirado a la movilidad. De hecho, la superficie preferida de los escritores neoyorquinos no fue el estático muro urbano sino el dinámico vagón de metro, y esto por razones relacionadas con ese "hacerse ver" (getting up) que explicamos más arriba. A diferencia del muro, el vagón de metro era una superficie que podía hacer circular tu nombre de un extremo a otro de la ciudad. El hecho de inscribir el graffiti en un soporte móvil como es el vagón de metro dotaba a éste de una movilidad que otras formas tradicionales de escritura mural no tuvieron, y en esto el moderno graffiti neoyorquino representa otra novedad con respecto al graffiti tradicional. Esta voluntad de liberar el graffiti del espacio estático del muro y ponerlo a circular por otros lugares a través de los vagones de metro y sus respectivas extensiones metonímicas (vagones de tren, furgonetas de reparto, autobuses, etc.), tiene que ver con esa búsqueda de fama y reputación a través del "hacerse ver" de manera prolífica. Así, si como decía Baudrillard (1980: 93), los graffiti "son del orden del territorio", el hecho de tener tu nombre circulando de un extremo a otro de la ciudad no suponía ya la conquista o territorialización de tal calle o tal barrio, sino, simbólicamente, de la ciudad entera.

La movilidad asociada a estos vagones de metro fue un factor clave a la hora de visibilizar el propio nombre y llevarlo más allá de una calle o un barrio concreto, pero su alcance quedaba restringido al ámbito de la propia ciudad, o como mucho, sus afueras. El transporte local que facilitaban estos vagones no puede compararse con el tipo de transporte global que trajo consigo la aparición de Internet y sus "autopistas de la información" (según la famosa expresión popularizada durante los primeros años de la revolución digital). Internet, como vehículo electrónico de información y conocimiento, permitió a los graffiteros hacer circular y dar a conocer sus nombres y obras alrededor del mundo. A partir de entonces, la difusión y conocimiento del graffiti se volvería inseparable de la mediación de las pantallas, las pantallas de los ordenadores, primero, y las pantallas de tablets y smartphones, después. De hecho, la pantalla será en muchas ocasiones la única forma de acceder y conocer obras de graffiti situadas en ciudades alejadas de nuestro propio entorno urbano. Así mismo, Internet permitió que graffiteros o aspirantes a graffiteros que antes podían estar aislados en pequeñas comunidades pudieran "viajar" electrónicamente a través de sus pantallas y, así, compartir sus gustos e intereses y relacionarse con un grupo 
más amplio de personas. También hizo posible una mayor contaminación estilística y apertura a otras formas de graffiti y de intervención urbana, más allá del modelo neoyorquino predominante. De hecho, esta es una de las razones por las que actualmente muchos prefieren hablar de street art o postgraffiti, y no ya de graffiti a secas, pues mientras que el término graffiti, en su acepción moderna, sigue estando muy vinculado al modelo neoyorquino, términos como street art o postgraffiti pretenden ser más abarcadores e inclusivos, no sólo en cuanto al estilo y las temáticas tratadas, sino también en cuanto a la variedad de técnicas utilizadas (stickers, stencils, posters, azulejos, etc.). Ambos términos son adecuados para una época que Lipovetsky y Serroy (2015: 43) han caracterizado como de "inflación estética", una era descentrada, desjerarquizada, y estructuralmente ecléctica en la que proliferan prácticas y experiencias artísticas profundamente heteróclitas, como aquellas que encontramos en el complejo mundo del street art o postgraffiti.

\section{Street art/postgraffiti, o el transeúnte como participante}

En ese proceso de diseminación digital instantánea que caracteriza al graffiti actual (Irvine, 2012), tan importantes como las propias imágenes capturadas por los propios autores de la obra son todas aquellas capturas realizadas por los propios transeúntes. Muchas de las imágenes de graffiti que encontramos actualmente en Internet provienen de fotografías tomadas por los propios paseantes, quienes al toparse, muchas veces de forma azarosa, con piezas de este tipo, no dudan en fotografiarlas y compartirlas a través de Internet. Redes sociales como Facebook, o aquellas más relacionadas con la práctica fotográfica como Flickr o Instagram, están repletas de imágenes de graffiti subidas por los propios transeúntes, quienes contribuyen así a una mayor visibilización y conocimiento de este tipo de piezas. Esta participación activa del público a la hora de visibilizar esta forma artística es otra de las características fundamentales del graffiti actual, y otra de las razones por las que algunos autores prefieren expresiones que pretenden ir más allá de este término, como las de street art o postgraffiti.

Según Javier Albarca (2010), en el street art el viandante está invitado a participar. Y esto porque las piezas de street art (muchas de ellas en diálogo intertextual con otros medios y artes), son mucho más entendibles que las formas abstractas del graffiti, más difíciles de apreciar y entender para el común de los viandantes. Según Albarca, el postgraffiti o street art es casi siempre gráfico y rara vez textual. Lo que se repite no es un nombre ilegible, como en el graffiti, sino un motivo o estilo gráfico reconocible con el que cualquier viandante se puede identificar y que puede abarcar desde imágenes de políticos hasta personajes de películas, series de dibujos animados o videojuegos. Esta identificación lleva al viandante a querer capturar y compartir digitalmente la pieza que está observando, y así, eventualmente, entrar en diálogo "pantallológico" con otras personas.

La participación del viandante es, pues, algo fundamental en el street art, tanto a nivel simbólico mediante su identificación con aquello que ve, como a nivel práctico mediante la captura digital de esa pieza (o piezas) y su puesta en circulación a través de Internet. Los propios artistas de street art son conscientes de esta voluntad de participación de los transeúntes, y algunos de ellos han ideado nuevas e interesantes 
formas de interacción con el público difíciles de encontrar en el modelo neoyorquino de graffiti. Un ejemplo paradigmático en este sentido es el del artista francés Invader, quien desde el año 1998 lleva desarrollando un proyecto a larga escala conocido como Space Invaders y directamente inspirado en el popular videojuego del mismo nombre desarrollado por Toshihiro Nishikado en 1978. Invader tomó este videojuego como punto de partida para su proyecto artístico, cuyo objetivo es "invadir" el mayor número de ciudades del planeta a partir de una práctica artística muy interesante: el empleo de azulejos para formar mosaicos que recrean de forma material y "artesanal" los famosos marcianitos del videojuego Space Invaders y su característica estética pixelada.

Una de las últimas creaciones de Invader es una aplicación para smartphones denominada "Flash Invaders", la cual permite a los usuarios localizar sus obras en la calle, fotografiarlas y compartirlas digitalmente. El objetivo de la app es que los usuarios capturen los famosos mosaicos de Invader con su teléfono móvil y competir unos con otros para ver quién consigue capturar más fotos y obtener, así, más puntos. Mediante esta aplicación los transeúntes devienen jugadores, y la práctica de fotografiar y compartir digitalmente piezas de street art a través de sus pantallas se $g a$ mifica, en el sentido de que se le incorporan técnicas, estéticas, y dinámicas propias del mundo de los videojuegos, como el hecho de obtener puntos por capturar fotos. ${ }^{4}$ Invader involucra así a los transeúntes en su propia obra, haciéndoles participe de la misma a través de un sencillo juego de capturar y compartir sus famosos mosaicos urbanos a través de sus pantallas.

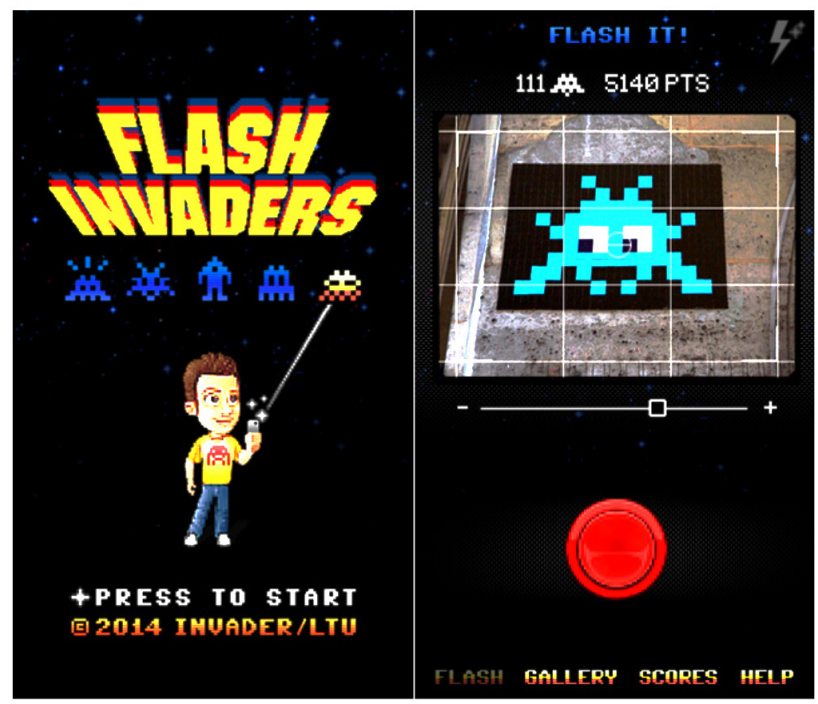

Figura 1. Imagen de la app Flash Invaders.

Fuente: http://golem13.fr/flashinvaders/

Para una discusión sobre los orígenes, definición y características de la "gamificación" véase Deterding et al. (2011). 
A pesar de las diferencias en cuanto a estilos, temáticas y técnicas empleadas, el street art o postgraffiti comparte con el graffiti neoyorquino la insistencia en el "dejarse" o "hacerse ver" (getting up), acción (o conjunto de acciones) que, como vimos, constituye la directriz primordial del graffiti moderno (Castleman, 1987). Pero si en el graffiti neoyorquino este "hacerse ver" se limitaba única y exclusivamente a superficies físicas como muros o vagones de metro, en el contexto del street art o postgraffiti, tan importante como "hacerse ver" en estos espacios físicos tradicionales es hacerlo -con igual o mayor insistencia- en los nuevos espacios digitales propios de la cibercultura (buscadores, blogs, wikis, redes sociales, etc.). Así mismo, mientras que en el graffiti neoyorquino este trabajo de difusión, expansión, o, por decirlo con un término más propio de nuestros tiempos, "viralización", del propio nombre y la propia obra dependía únicamente de los mismos graffiteros, en el street art o postgraffiti los transeúntes y usuarios de Internet contribuyen a esta lógica del "hacerse ver" capturando, subiendo, compartiendo y comentando piezas de street art a través de sus pantallas. Así, ya no es el graffitero el único responsable de "hacer ver" y expandir su trabajo, sino que el propio público participa y coopera en esta tarea compartiendo, comentando y "viralizando" su nombre y sus piezas a través de Internet.

Esta insistencia en la participación del público en el ámbito del street art o postgraffiti es propio del régimen de la cibercultura y el ciberarte, donde, como ha señalado Pierre Lévy (2007: 108), uno de los caracteres más constantes es "la participación en las obras de los que las prueban, las interpretan, las exploran o las leen". Pero no solamente participación en la construcción del sentido, sino participación en el sentido de una coproducción de la obra, puesto que "el 'espectador' es llamado a intervenir directamente en la actualización (la materialización, la exposición, la edición, el desarrollo efectivo aquí y ahora) de una secuencia de signos o de acontecimientos".

Por último, no es sólo que los transeúntes sean llamados a participar e intervenir directamente en las obras de street art o postgraffiti, sino que ellos mismos pueden crear este tipo de piezas. Solamente en YouTube es posible localizar multitud de tutoriales donde se nos explica con todo tipo de detalles cómo realizar stencils y otras técnicas de street art, de modo que cualquiera de nosotros puede acceder fácilmente a este tipo de información sobre la producción y puesta en práctica del street art. Este tipo de información no existía en los tiempos del graffiti neoyorquino, donde el conocimiento de la técnica se obtenía más bien entrando directamente en la escena y pidiendo a escritores experimentados que le enseñaran a uno los rudimentos de su arte (Castleman, 1987). En el street art, cualquier persona puede potencialmente aprender a hacer stencils o diseñar pegatinas y pósters a través de vídeos tutoriales disponibles en YouTube, por lo que se trata de un tipo de arte mucho más democrático que el tradicional graffiti neoyorquino. A ello se suma la mayor facilidad de diseñar una plantilla de stencil, una pegatina o un póster, que dominar con soltura el tipo de lenguaje verbovisual, o "escripto-icónico" (Gubern, 1992), del graffiti, un lenguaje que en casos como el del Wildstyle o "estilo salvaje" puede resultar tremendamente complicado de aprender. Así mismo, programas de edición digital como Photoshop o Illustrator permiten a los propios artistas de street art y a todos aquellos interesados en poner en práctica este tipo de arte, diseñar y preparar esbozos de las piezas que quieren realizar y experimentar con ellas en el espacio dinámico (y seguro) de la pantalla antes de trasladarlas a un muro o a cualquier otro tipo de super- 
ficie urbana. Existen, además, varias apps que permiten hacer graffitis digitales en la pantalla de su smartphone y/o tablet, desde escribir el propio nombre de uno con una estética graffitera hasta simular que pintamos una pared real a partir de la tecnología de la realidad aumentada, tal y como sucede en el caso de la aplicación Street Tag.
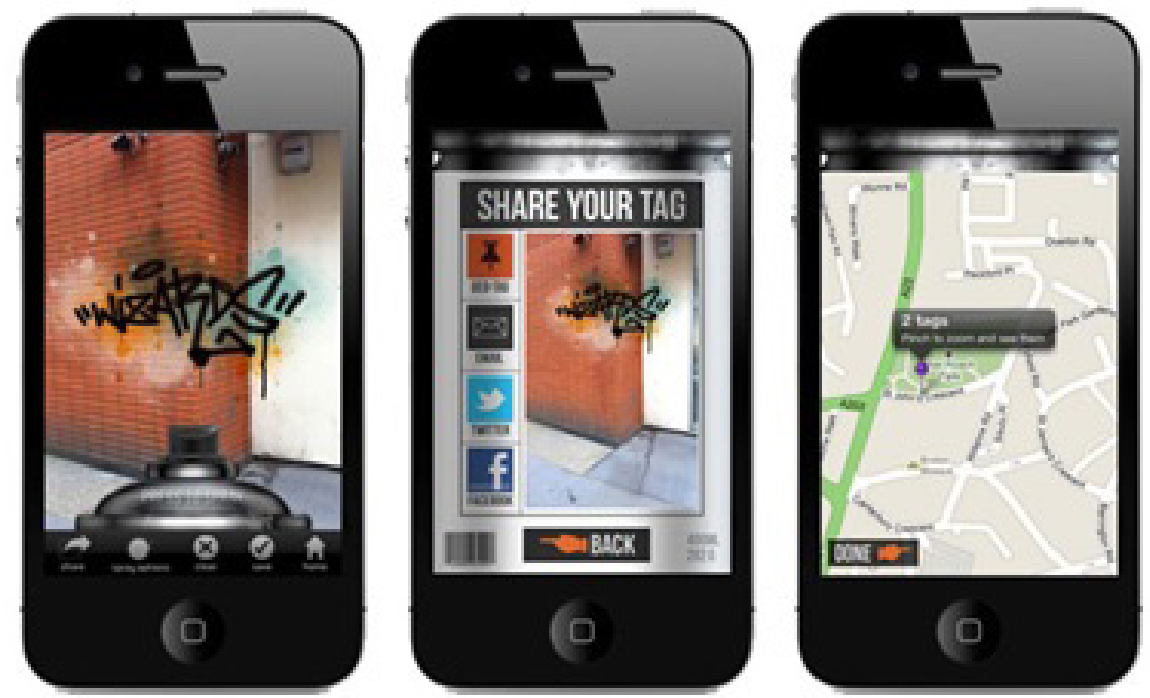

Figura 2. Imagen de la app Street Tag.

Fuente: http://www.funkyspacemonkey.com/street-tag-app-iphone-ipad-2-video

En casos como el de Street Tag, la propia esencia del graffiti como práctica subversiva y transgresora queda en entredicho, pues permite que cualquiera pueda intervenir y transgredir los espacios urbanos desde la comodidad y seguridad de su pantalla y sin el riesgo real de ser multado o detenido. Se trata de la máxima expresión de este proceso de "pantallización" del graffiti que aquí hemos tratado de analizar: graffitis que únicamente existen en el espacio digital de la pantalla y que no tienen una correspondencia real en el mundo físico; graffitis que no existen ya en el muro tangible y real, que no "ensucian" y "manchan" el muro físico oficial sino el "muro" digital, lúdico y seguro de la pantalla; graffitis-pantalla, en definitiva, que democratizan y expanden la práctica graffitera, pero que también banalizan y desvirtúan su propia esencia y razón de ser.

\section{Conclusiones}

Como hemos visto a lo largo de este artículo, la irrupción de Internet y la cibercultura ha transformando muchos de los aspectos relacionados con la práctica, el significado y la experiencia del graffiti tal y como lo conocíamos desde que el graffiti neoyorquino se impusiera como modelo predominante durante los años 80 del siglo XX. El graffiti es hoy en día completamente inseparable de la mediación de pantallas interactivas como las del ordenador o los smartphones. En la actualidad, los pro- 
cesos de producción, distribución y consumo de graffiti -así como del denominado street art o postgraffiti- tienen lugar a través de pantallas diversas que se conectan y comunican entre sí: pantallas en red operando en el interior de una "sociedad red" (Castells, 2005). No hay duda, por tanto, de que el graffiti se ha "pantallizado", y el espacio físico del muro como lugar privilegiado de la experiencia graffitera -y sus ya mencionadas extensiones metonímicas (vagones, señales de tráfico, etc.)- ha ido cediendo paso al espacio digital de la pantalla, donde los graffitis pueden ser fácilmente localizados, diseñados, editados, distribuidos, archivados, estudiados, simulados, remixados, mashapeados, etc.

En las pantallas de ordenadores, tablets y smartphones, los graffitis adquieren a través de su digitalización una fluidez, movilidad y "liquidez" (Bauman, 2007) que choca con el carácter sólido y estático de sus formas murales tradicionales. En este tipo de pantallas, el graffiti se desmaterializa y cambia su textura de átomos por una textura de bits que nos permite experimentar y jugar con sus formas a través de diferentes programas y aplicaciones. De ahí que cualquier obra de graffiti disponible actualmente en Internet esté potencialmente abierta a todo tipo de lecturas, apropiaciones y reformulaciones por parte de los usuarios, generando una "semiodinámica textual" que es "simultáneamente transitiva y reflexiva (read/write): idiosincrática e ideosincrética, permite la negociación dinámica y permanente de la textualidad en red" (Fabbri, 2012: 7). Y es que, una vez online, la obra "material" de graffiti deviene obra "virtual", y la obra virtual, como recuerda Lévy (2007: 108), es "abierta" por definición, pues favorece un proceso de creación continua en el que "el acontecimiento de la creación ya no está limitado al momento de la concepción o de la realización de la obra: el dispositivo virtual propone una máquina para hacer surgir acontecimientos". En este sentido, el carácter físico y material de los graffitis, es decir, el acto de realización del mismo en un muro, señala de tráfico o vagón de tren, es sólo un momento, efímero y fugaz, dentro de la cadena de acontecimientos digitales que actualmente acompañan a este acto indicial (en el sentido semiótico de marca o huella), desde su captura fotográfica con una cámara o smartphone hasta su diseminación digital instantánea por los múltiples espacios de la red (blogs, foros, redes sociales, etc.). El resultado de todo ello es una proliferación sin precedentes de imágenes y experiencias de graffiti mediadas por pantallas -esos nuevos "muros" interactivos del siglo XXI-, y la construcción, siempre en proceso de actualización, de la mayor base de datos de arte urbano de la historia, igualmente accesible a través de pantallas.

\section{Referencias:}

Abarca, Javier (2010). El postgraffiti, su escenario y sus raices: graffiti, punk, skate y contrapublicidad. Madrid. Universidad Complutense de Madrid.

Baudrillard, Jean (1980). "Kool Killer o la insurrección del signo". En: El intercambio simbólico y la muerte. Caracas. Monte Avila Editores.

Bauman, Zygmunt (2007). Modernidad líquida. Buenos Aires. Fondo de cultura económica. Cardoso, Gustavo y Lima, Tiago (2013). "Sociología de la mediación y de las pantallas". En: Cardoso, G. (ed.), Sociología de las pantallas. Barcelona. Editorial UOC.

Castells, Manuel (2005). La era de la información (vol. 1): La sociedad red. Madrid. Alianza. 
Castleman, Craig (1987). Los graffiti. Madrid. Hermann Blume.

Derrida, Jacques (1997). Mal de archivo. Una impresión freudiana. Madrid. Trotta.

Deterding, Sebastian, Dixon, Dan, Khaled, Rilla, y Nacke, Lennart (2011). "From game design elements to gamefulness: defining 'gamification"'. En: Proceedings of the 15th International Academic MindTrek Conference, pp. 9-15.

Fabbri, Paolo (2012). "La era remix". Revista de Occidente, no 370, marzo 2012, pp. 5-11.

García Canclini, Néstor (1990). Culturas Hibridas. Estrategias para entrar y salir de la modernidad. México. Grijalbo.

Garí, Joan (1995). La conversación mural. Ensayo para una lectura del graffiti. Madrid. Fundesco.

Gubern, Román (1992). La mirada opulenta. Exploración de la iconosfera contemporánea. Barcelona. Gustavo Gili.

Hatzfled, Marc (2007). La cultura de los suburbios. Barcelona. Laertes.

Irvine, Martin (2012). “The Work on the Street: Street Art and Visual Culture.” En: Heywood, I. y Sandywell, B (eds.), The Handbook of Visual Culture, London, Berg, pp. 235-278.

Lévy, Pierre (2007). Cibercultura. La cultura de la sociedad digital. Barcelona. Anthropos.

Lipovetsky, Gilles, y Serroy, Jean (2015). La estetización del mundo. Vivir en la época del capitalismo artístico. Barcelona. Anagrama.

Manovich, Lev (2006). El lenguaje de los nuevos medios de comunicación. La imagen en la era digital. Barcelona: Paidós.

Martín Barbero, Jesús (1987). De los medios a las mediaciones. Comunicación, cultura y hegemonía. México. Gustavo Gili.

_ (2008). "Lo público: experiencia urbana y metáfora ciudadana". CIC. Cuadernos de información y comunicación, $\mathrm{n}^{\mathrm{o}}$ 13, pp. 213-226.

Stahl, Johaness (2009). Street Art. Potsdam. H.F.Ullmann. 